spherical or spheroidal micelles); the molecules of thd alcohols and fatty acids are, however, incorporated between the colloid molecules in the palisade layers and thus increase the mount of micelle-forming matter. Solubilization data of the type on which curves 1 a and $1 \mathrm{~b}$ in Fig. $1 \mathrm{~B}$ are based have been considered to support this view and to prove the existence of two loci of solubilization in the mioelles 8,0 .

The experiments described in curves 2 and 3 in Fig. 1 B show that the alcohols and fatty aoids on one hend and hydrocarbons on the other, are initially solubilized quite independently by the bile salt micelles. This can be considered to indicate that the polar-nonpolar compounds and hydrocarbons are solubilized in different loci in the bile salt micelles. A marked difference as compared with the paraffin chain colloids is, however, that the polar-nonpolar compounds are built in the bile salt micelles in such a manner that the power of the micelles to solubilize hydrocar. bons is not increased; on the contrary, the in. corporation of larger amounts of the polarnonpolar compounds progressively diminishes the power to solubilize hydrocarbons. It is thus evident that the mode in which the polar. nonpolar compounds are built in the micelles differs for the bile and paraffin chain salts.

One of the present authors has called atten. tion to the fact that the maximum amounts of fatty acids that sodium taurocholate solutions are able to solubilize are so great ${ }^{3}$ (from about 2 moles of nonylic acid to 5 moles of caproic acid per mole of taurocholete in $0.09 \mathrm{M}$ solution) that it must be assumed that the structure of the micelles is altered to such an extent that mixed micelles with completely new properties are formed. Also the maximum amounts of long-chain alcohols solubilized by bile salt micelles are fairly large (1-2 moles per mole of the bile selt). According to the data presented here altered properties of the micelles become apparent only after the mole ratio of polar-nonpolar compound and bile selt exceeds a certain velue, which is about 0.14 for decanol and sodium cholate, 0.34 for decanol and sodium taurodesoxycholate, and 0.8 for nonylic and 1.3 for heptylic acid and sodium taurodesoxycholate. A change in micellar structure apparently occurs only after thees values of the ratio are exceeded.

All the above mentioned data show that there exist important differences in the solubilization mechanism in the case of bile salts and paraffin chain salts, particularly in regard to the location of solubilized molecules in the micelles and the interaction between the solubilizer and solubilizete. This is evidently con- nected with essential differences in the struc. tures of the micelles of the two types of asso. ciation colloids.

1. Ekwall, P. Acta Acad. Aboensis, Math. Phys. XVII (1951) 8.

2. Ekwall, P. Svensk Kem. Tidskr. 63 (1951) 973.

3. Ekwall, P. Koninkl. Vlaam. Acad. Veten. schap. Intern. conference on Biochemical Problems of Lipids. Brussels 1953, p. 103.

4. Ekwall, P. J. Colloid Sci. Suppl. 1 (1954) 66.

5. Ekwall, P. and Danielsson, I. Acta Chem. Scand. 5 (1951) 973.

6. Ekwall, P., Passinen, K. and Danielsson, I. Finska Kemistsamfundets Medd. 63 (1954) 1.

7. Passinen, K. and Ekwall, P. Acta Chem. Scand. 9 (1955) 1438, 1450.

8. Klevens, H. B. J. Chem. Phys. 17 (1944) 1004.

9. Klevens, H. B. J. Am. Chem. Soc. 72 (1950) $3581,3780$.

Received April 14, 1956.

Can Micelles be Treated as Ideal Mixtures of Ions and Neutral Molecules?

JURI BEIM, LARS GUNNAR SILLEN and ULF ULFVARSON

Department of Inorganic Chemistry, Royal Institute of Technology, Stockholm 70, Sweden

In the last few years, attempts have Ibeen made in this Institution to study equilibria involving micelles of carboxylic acids such as lauric acid, $\mathrm{C}_{11} \mathrm{H}_{23} \mathrm{COOH}=$ HL, and amines like dodecyl amine $\mathrm{C}_{12} \mathrm{H}_{25} \mathrm{NH}_{2}=\mathrm{D}$. Emf titrations have been made (using glass or hydrogen electrodes, sometimes Ag, AgL electrodes) with a practically constant ionic medium, in order to keep the activity factors constant. In each titration, the total concentration $B=\left[H_{L}\right]_{t}+\left[\mathrm{L}^{-}\right]_{t}$ or $[\mathrm{D}] \mathrm{t}+\left[\mathrm{DH}+\mathrm{t}_{\mathrm{t}}\right.$ has been kept constant, and the data have been given in the shape of a plot $Z(\log h)_{B}$, 


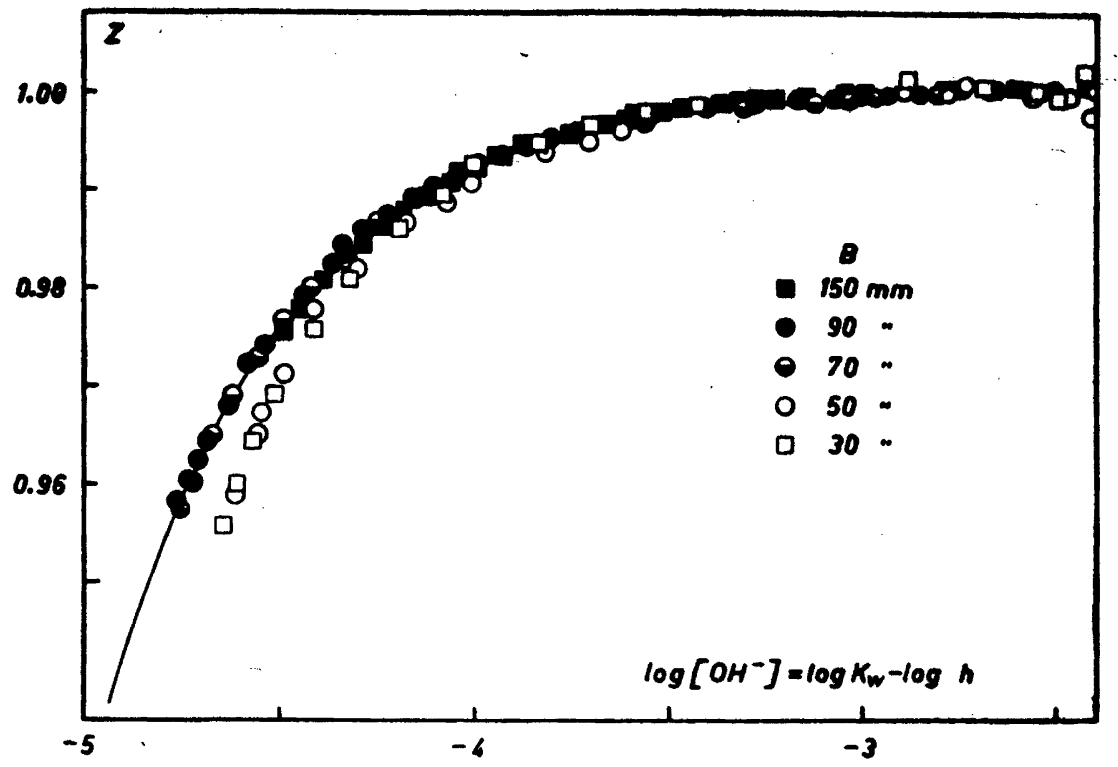

Fig. 1. $\mathrm{Z}\left(\log \mathrm{K}_{\mathrm{w}}-\log \mathrm{h}\right)_{B}$ for potassium laurate solutions in $1 \mathrm{~m} \mathrm{KNO}$ at $25^{\circ} \mathrm{C}$. Points: experimental points for five total concentrations. Curve: calculated for monoprotic acid with $p \mathrm{~K}_{\mathrm{w}}-p \mathrm{~K}_{\mathrm{a}}=6.11$.

where $h=\left[H^{+}\right]$and $Z$ is the average charge per unit, thus $B Z=\left[\mathrm{L}^{-}\right] \mathrm{t}$ or $[\mathrm{DH}+]_{\mathrm{t}}$. Theae experiments have met with many difficulties and are still in progress. We would however like to draw attention to one of the results obtained.

Fig. 1 gives the data $Z(\log h)_{B}$ for lauric acid, obtained by one of us (J.S.). Ionic medium $1 \mathrm{~m} \mathrm{~K}^{+}\left(\mathrm{NO}_{3}^{-}\right), 25^{\circ} \mathrm{C}$, glass elec. trode. The abscissa is really $\log \left[\mathrm{OH}^{-}\right]=$ $\log K_{\mathrm{w}}-\log h$. In the range $Z=1.0$ to 0.95 , reversible equilibris were achieved since the same curves were obtained when $\mathrm{HNO}_{3}$ or KOH was added; for lower values of $Z$, precipitates appeared which dissolved but alowly on addition of KOH. For lower values of $B$, there were also difficulties with the equilibria.

In the concentration range given, 30 to $150 \mathrm{~mm}$, the mejor part of the laurate groups would be present in the form of micelles. Using the method of Ekwall and Harva ", we found the maximum concen. tration of free $\mathrm{L}^{-}$to be about $6 \mathrm{~mm}$ at $50^{\circ} \mathrm{C}$. From data of Corrin and Harkins ", one may estimate the critical concentration to be about $2.5 \mathrm{~mm}$.

One may calculate what the shape of
$Z(\log h)_{B}$ would have been under various simple assumptions concerning the phases and dissolved species present. At equilibrium between two solid phases of con. stant composition, such as $\mathrm{KL}(\mathrm{s})+$ $\mathrm{HL}(\mathrm{s})$, or $\mathrm{KL}(\mathrm{s})+\mathrm{KHL}_{\mathbf{g}}(\mathrm{s}), \log h$ would be constant. If the main resction is equilibrium between $\mathrm{L}^{-}$in solution and $\mathrm{KHL}_{3}(\mathrm{~s})$ or $H L(8)$, the slope of $Z(\log h)$ would also have been much steeper than that actually found. Moreover, the curve would have shifted with varying values of $B$.

Assuming equilibrium between $\mathrm{KL}(\mathrm{s})$ and $\mathrm{HL}$ or $\mathrm{HL}_{2}{ }^{-}$in solution, one would get curves of the right shape, but the curves would have been shifted with an amount equal to the shift in $\log B$. According to experiment, the points for 70,90 , and 150 mm practically coincide, and the devis. tions for 30 and $50 \mathrm{~mm}$ are only about 0.1 units, wherees $\log 150 / 30=0.7$. Thus, none of these assumptions is valid.

However, a very good fit is found with the simple curve $Z=K_{\mathrm{a}} h^{-1}\left(1+K_{\mathrm{a}} h^{-1}\right)^{-1}$, calculated for the dissociation of a monoprotic acid, with $\mathrm{p} K_{\mathrm{w}}-\mathrm{p} K_{\mathrm{a}}=6.11$. Assuming $\mathrm{p} K_{w} \approx 13.7$ one obtains $\mathrm{p} K_{a} \approx \mathbf{7 . 6}$. The simple explanation that the solution 

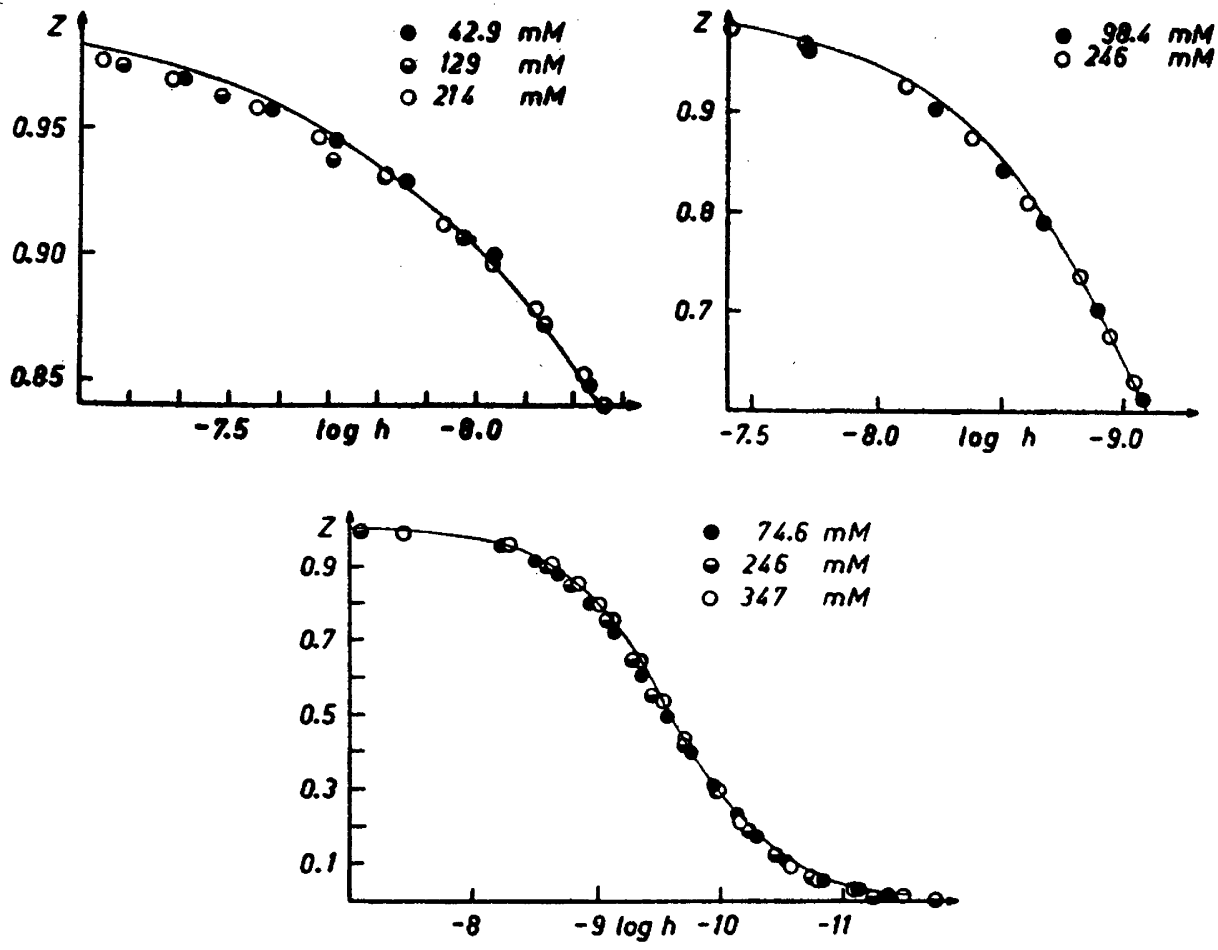

Fig. $2 a-c . \mathrm{Z}(\log \mathrm{h})_{B}$ for dodecyl ammonium chloride solutions in $0.5 \mathrm{M} \mathrm{NaClat} 25^{\circ} \mathrm{C}$ with a) 1.70 , b) 4.75 , c) $6.78 \mathrm{M} \mathrm{C}_{2} \mathrm{H}_{5} \mathrm{OH}$. Curves:calculated for simple equilibrium $\mathrm{DH}^{+} \rightleftharpoons \mathrm{D}+\mathrm{H}^{+}$, with a) $\left.\left.p \mathrm{~K}_{\mathrm{a}}=8.97, p \mathrm{~K}_{\mathrm{w}}=13.96 ; b\right) p \mathrm{~K}_{\mathrm{a}}=9.27, p \mathrm{~K}_{\mathrm{w}}=14.03 ; c\right) p \mathrm{~K}_{\mathrm{a}}=9.62, p \mathrm{~K}_{\mathrm{w}}=14.09$.

would contain only single molecules $H L$ and $\mathrm{L}^{-}$is ruled out already by the fact that, for lower values of $B$, the curves $Z(\log h)_{B}$ break away from the curve in Fig. 1. Nor would it be consistent with what is known about the micellar behavior.

The simplest way of expressing our results is perhaps treating the micelles formally as a separate phase, a mixture of $\mathrm{L}^{-}$ and $\mathrm{HL}$ (perhaps also $\mathrm{K}^{+}, \mathrm{NO}_{3}{ }^{-}$, and $\mathrm{H}_{2} \mathrm{O}$ from the ionic medium). Then our results would imply that, in the range where this phase is stable $\left(x_{\mathrm{HL}}=0\right.$ to 0.05$)$, it is approximately an ideal mixture of $\mathrm{L}^{-}$and HL. A similar picture has been given by Stainsby and Alexander ${ }^{3}$; at that time it was supported only by measurements of the hydrolysis of pure soap solutions with varying ionic strength.

One might speculate on why the acid is so much less willing to give off a proton than normal carboxylic acids in aqueous solution ( $\mathrm{p} K_{\mathrm{a}}=4$ to 5 ). A related fact is the observation of Ekwall 4 that monolayers of myristic acid show a large ioniza. tion effect around $\mathrm{pH} \approx 8-10$.

Fig. 2 gives analogous results, obtained by one of us (U.U.), for dodecyl ammonium chloride $\left(\mathrm{DH}+\mathrm{Cl}^{-}\right)$. The ionic medium was $0.5 \mathrm{M}\left(\mathrm{Na}^{+}\right) \mathrm{Cl}^{-}$, with three different concentrations of $\mathrm{C}_{2} \mathrm{H}_{5} \mathrm{OH}(1.70,4.75$, and $6.78 \mathrm{M})$. For each concentration of $\mathrm{C}_{2} \mathrm{H}_{5} \mathrm{OH}$, two or three different total concentrations $B$ were used, all in a range in which the micelles would predominate, even without adding $\mathrm{NaCl}$, according to the conductivity data of Ralston and Hoerr 4 .

In this case too, the $Z(\log h)$ curves seem to be independent of the total concentration $B$, and to coincide surprisingly well with those calculated for a simple equi- 
librium between dissolved $B$ and $B H^{+}$, with $\mathrm{p} K_{\mathrm{a}} \approx 8.9$ to 9.6 . If the previous conductivity data have been interpreted correctly, we are once more brought to the approximation of the micelle as an ideal mixture; for $D$ and $D^{+}$, the range of $Z$ is moreover much wider than it was for lauric acid.

The work on lauric acid has been supported by a grant from Statens Naturvetenskapliga Forskningarad (Swedish Natural Science Research Council).

1. Ekwall, P. and Harva, O. Finska Kemistsamfundets Medd. 52 (1943) 257.

2. Corrin, M. L. and Harkins, W. D. J. Am. Chem. Soc. 69 (1947) 683.

3. Stainsby, G. and Alexander, A. E. Trans. Faraday Soc. 45 (1949) 585.

4. Ekwall, P. Svensk Kem. Tidskr. 63 (1951) 277.

5. Ralston, A. W. and Hoerr, C. W. J. Am. Chem. Soc. 68 (1946) 851.

Received April 19, 1956.

\section{Preparation of Di-p-nitrobenzyl-} phosphoryl chloride via the Corresponding Phosphite

GEORG FOLSCH

Department of Medical Biochemistry, University of Gothenburg, Gothenburg, Sweden

The very promising phosphorylating 1 reagents recently introduced by Leonidas Zerwas and collaborators, e. $g$. di-pnitrobenzylphosphoryl chloride, were originally synthesized by procedures involving silver selt esterifications ${ }^{1}$. For preparation of these reagents in large batches it seems to be preferable to use the phosphite route ${ }^{2,3}$. In connection with syntheses of phosphopeptides ${ }^{4}$ we have obtained di-p. nitrobenzyl phosphite in good yield from p-nitrobenzyl alcohol and phosphorus trichloride. This phosphite gives, as ex. pected, the desired phosphoryl chloride quantitatively by chlorination with sulphuryl chloride.

Experimental. Di-p-nitrobenzyl phosphite. To a vigorously stirred solution of $27.6 \mathrm{~g}$ phosphorus trichloride $(1 \mathrm{~mole})$ in $600 \mathrm{ml}$ dry benzene of room temperature a warm solution of $61.2 \mathrm{~g} p$-nitrobenzyl alcohol (2 moles) and $48.4 \mathrm{~g}$ dimethylanilin (2 moles) in $200 \mathrm{ml}$ benzene was added in small portions within one hour. After an additional hour of stirring, $30.6 \mathrm{~g} p$-nitrobenzyl alcohol (1 mole) in 200 ml benzene was added within 20 minutes. The mixture was stirred for a further two hours and then left overnight. The benzene solution was washed with water $(3 \times 200 \mathrm{ml}), 5 \mathrm{~N}$ ammonia $(2 \times 200 \mathrm{ml})$, water $(2 \times 200 \mathrm{ml})$ and dried over anhydrous sodium sulphate. By addition of light petroleum, di-p-nitrobenzyl phosphite separated as white crystals. The yield was $43.5 \mathrm{~g}$ (62 \% of the theoretical). The phosphite was recrystallized from ethanol or chloroform-cyclohexane. M. p. $\mathbf{7 5}^{\circ}$. (Found: C 47.70; H 3.70; N 7.91; P 9.00. Calc. for $\mathrm{C}_{14} \mathrm{H}_{13} \mathrm{O}_{7} \mathrm{~N}_{2} \mathrm{P}$ : C 47.70; $\mathrm{H} .72 ; \mathrm{N} 7.96 ; \mathrm{P} 8.81$ ).

Chlorination. To a suspension of $35.3 \mathrm{~g}$ phosphite in $250 \mathrm{ml}$ carbon tetrachloride $8 \mathrm{ml}$ sulphuryl chloride was added dropwise with shaking. Dry nitrogen was slowly bubbled through the mixture and the temperature was held under $20^{\circ}$. After 20 minutes the solvent was removed in vacuo and the solid dissolved in chloroform. Addition of light petroleum gave white crystals of di-p-nitrobenzylphosphoryl chloride $(36.0 \mathrm{~g}=93 \%)$ with the m. p. $107-108^{\circ}$. The mixed melting point with phosphoryl chloride prepared according to Zerwas ${ }^{1}$ showed no depreasion. (Found: P 7.91; Cl 8.89. Calc. for $\mathrm{C}_{14} \mathrm{H}_{12} \mathrm{O}_{7} \mathrm{~N}_{2} \mathrm{PCl}$ : P 8.00; Cl 9.16).

1. Zerwas, L. and Dilaris, I. J. Am. Chem. Soc. 77 (1955) 5354.

2. Atherton, F. R., Openshaw, H. T. and Tood, A. R. J. Chem. Soc. 1945382.

3. Miyano, M. and Funahashi, S. J. Am. Chem. Soc. 77 (1955) 3522.

4. Fölsch, G. Acta Chem. Scand. 9 (1955) 1039 .

Received May 8, 1956. 